\title{
Effects of Matrix Structure and Nitrogen Content on Fatigue Properties of Ultrahigh-Strength Low Alloy TRIP-Aided Steels
}

\author{
Tomohiko HOJO, ${ }^{1) *}$ Junya KOBAYASHI, ${ }^{2)}$ Koh-ichi SUGIMOTO, ${ }^{3)}$ Yoshito TAKEMOTO, ${ }^{4)}$ Akihiko NAGASAKA, ${ }^{5)}$ \\ Motomichi KOYAMA $^{11}$ and Eiji AKIYAMA ${ }^{1)}$ \\ 1) Institute for Materials Research, Tohoku University, 2-1-1 Katahira, Aoba-ku, Sendai, 980-8577 Japan. \\ 2) Faculty of Engineering, Ibaraki University, 4-12-1 Nakanarusawa-cho, Hitachi, Ibaraki, $316-8511$ Japan. \\ 3) School of Science and Technology, Shinshu University, 4-17-1 Wakasato, Nagano, 380-8553 Japan. \\ 4) Graduate School of National Science and Technology, Okayama University, 3-1-1 Tsushima-Naka, Kita-ku, Okayama, 700- \\ 8530 Japan. \\ 5) National Institute of Technology, Nagano College, 716 Tokuma, Nagano, 381-8550 Japan.
}

(Received on June 30, 2020; accepted on August 18, 2020)

\begin{abstract}
To develop ultrahigh-strength steels for automotive impact safety parts, the effects of the microstructure and nitrogen content on the fatigue properties of ultrahigh-strength low alloy transformation-induced plasticity (TRIP)-aided steels with martensite (TM), bainitic ferrite-martensite (TBM), and bainitic ferrite (TBF) matrices were investigated. Compared to TBF steels, both the TM and TBM steels achieved high tensile strength, of more than $980 \mathrm{MPa}$, and excellent fatigue properties. This results from the suppression of crack propagation due to the effective TRIP of the relatively stable interlath retained austenite and the increase in tensile and yield strengths attributed to the low isothermal transformation treatment. The fatigue strengths of the ultrahigh-strength low alloy TRIP-aided steels were slightly increased by the addition of $100 \mathrm{ppm}$ of nitrogen. The increase in fatigue strength of TM, TBM, and TBF steels with 100 ppm of nitrogen was caused by the fine and uniform martensite and bainitic ferrite matrices and retained austenite, along with the increase in carbon concentration in the retained austenite due to the precipitation of AIN.
\end{abstract}

KEY WORDS: TRIP-aided steel; high-strength steels; fatigue properties; retained austenite; nitrogen.

\section{Introduction}

High-strength steel sheets, of 980 and $1180 \mathrm{MPa}$ grades, which are referred to as ultrahigh-strength steels, have been positively applied to automobile structural parts because of the reduction in weight and improvement in impact safety of the vehicles. The conventional ultrahighstrength steel sheets, with tensile strength of up to 1180 $\mathrm{MPa}$, have been applied to automotive structural parts after press forming. However, increasing tensile strength over $980 \mathrm{MPa}$ in the steels decreases not only press formabilities but also impact, fatigue properties and delayed fracture resistance. It is expected that the application of ultrahigh-strength low alloy transformation-induced plasticity (TRIP) ${ }^{1)}$-aided steels with bainitic ferrite matrix $(\mathrm{TBF} \text { steels })^{2-5)}$ will solve these problems. Moreover, TRIP-aided martensitic (TM) steels, ${ }^{6-9)}$ and TRIP-aided bainitic ferrite-martensite (TBM) steels $^{10,11)}$ have been developed to improve the tensile strength in comparison

\footnotetext{
* Corresponding author: E-mail: hojo@imr.tohoku.ac.jp
}

with TBF steels.

The simultaneous improvement in strength and corrosion resistance can be achieved by adding nitrogen to the austenitic steels ${ }^{12-15)}$ because of the solid solution effects and the precipitation of nitride. Thus, it is expected that the addition of nitrogen to TM, TBM, and TBF steels will improve their strength and corrosion resistance. Besides, the addition of nitrogen may improve their fatigue strength because the fatigue strength of metals, ${ }^{16}$ ) including TRIPaided steels, ${ }^{9,17)}$ increases with increasing tensile strength.

In this study, the effects of the matrix structure and nitrogen content on the fatigue properties of ultrahigh-strength low alloy TRIP-aided steels were investigated to develop advanced high-strength steels for automotive structural parts.

\section{Experimental Procedure}

Three types of cold rolled sheets, each of $1.2 \mathrm{~mm}$ in thickness and with the chemical composition presented in Table 1, were used in this study. Various nitrogen contents, of 
Table 1. Chemical compositions of steels used (mass $\%$ ).

\begin{tabular}{cccccccc}
\hline Steel & $\mathrm{C}$ & $\mathrm{Si}$ & $\mathrm{Mn}$ & $\mathrm{Al}$ & $\mathrm{Nb}$ & $\mathrm{N}$ & $M_{\mathrm{S}}$ \\
\hline $\mathrm{A}$ & 0.20 & 1.00 & 1.50 & 0.48 & 0.049 & 0.0009 & 434 \\
$\mathrm{~B}$ & 0.187 & 1.01 & 1.50 & 0.48 & 0.050 & 0.0106 & 438 \\
$\mathrm{C}$ & 0.176 & 1.04 & 1.50 & 0.53 & 0.052 & 0.0188 & 444 \\
\hline
\end{tabular}

$M_{\mathrm{S}}$ : martensite start temperature $\left({ }^{\circ} \mathrm{C}\right)$

(a)

$1200^{\circ} \mathrm{C}$

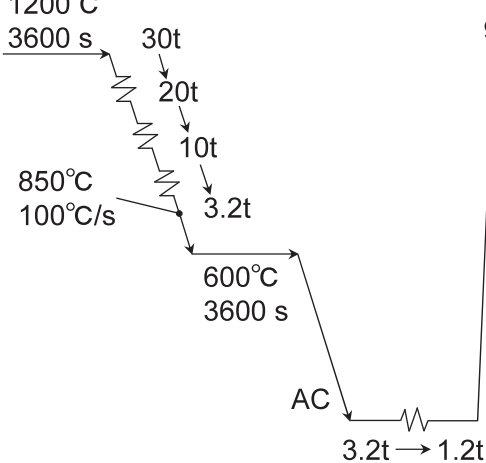

Fig. 1. (a) Hot and cold rolling processes and (b) annealing and isothermal transformation treatment processes of ultrahigh-strength low alloy TRIP-aided steels.

approximately 0,100 , and 200 mass ppm (hereafter ppm), were utilized in the steels, and the same amount of carbon content was removed to keep the sum of carbon and nitrogen contents constant $(\mathrm{C}+\mathrm{N}=0.2$ mass $\%)$. The steels containing 0,100 , and $200 \mathrm{ppm}$ of nitrogen were named as $\mathrm{A}, \mathrm{B}$, and $\mathrm{C}$, respectively. The martensite-start temperature $\left(M_{\mathrm{S}}\right),{ }^{18)}$ calculated by the following Eq. (1), is also listed in Table 1.

$$
\begin{aligned}
M_{\mathrm{S}}\left({ }^{\circ} \mathrm{C}\right)= & 550-361 \times(\% \mathrm{C})-39 \times(\% \mathrm{Mn})-0 \times(\% \mathrm{Si}) \\
& +30 \times(\% \mathrm{Al})-5 \times(\% \mathrm{Mo})
\end{aligned}
$$

where $\% \mathrm{C}, \% \mathrm{Mn}, \% \mathrm{Si}, \% \mathrm{Al}$, and $\% \mathrm{Mo}$ represent the contents of the individual alloying elements, respectively.

First, hot rolling from $30 \mathrm{~mm}$ to $3.2 \mathrm{~mm}$ followed by cold rolling to $1.2 \mathrm{~mm}$ thickness was conducted to the steels, as shown in Fig. 1(a). Then, the tensile and fatigue specimens were cut from the rolled sheets by laser processing. The sheet specimens were heat-treated to produce ultrahighstrength TRIP-aided steels (Fig. 1(b)). The TM steels were produced by annealing at $950^{\circ} \mathrm{C}$ for $1200 \mathrm{~s}$ and isothermal treatment at $250^{\circ} \mathrm{C}$ for $1000 \mathrm{~s}$ in salt baths. To produce the $\mathrm{TBM}$ and TBF steels, annealing at $950^{\circ} \mathrm{C}$ for $1200 \mathrm{~s}$ and isothermal treatment at 350 and $450^{\circ} \mathrm{C}$ for $1000 \mathrm{~s}$ in the salt baths were conducted, respectively.

The microstructure of the steels was observed by scanning electron microscope (SEM)-electron backscatter diffraction (EBSD) measurements. The sample was mounted in an acryl polymer and ground using waterproof papers of \#320, \#600, \#1 200, and \#2 000 grids, followed by polishing with 3 and $1 \mu \mathrm{m}$ single crystal diamond slurries, 0.3 and $0.05 \mu \mathrm{m}$ alumina suspensions, and $0.04 \mu \mathrm{m}$ colloidal silica for $30 \mathrm{~min}$ each. The EBSD analyses were conducted in an area of $40 \mu \mathrm{m} \times 40 \mu \mathrm{m}$ with a beam step size of $0.2 \mu \mathrm{m}$
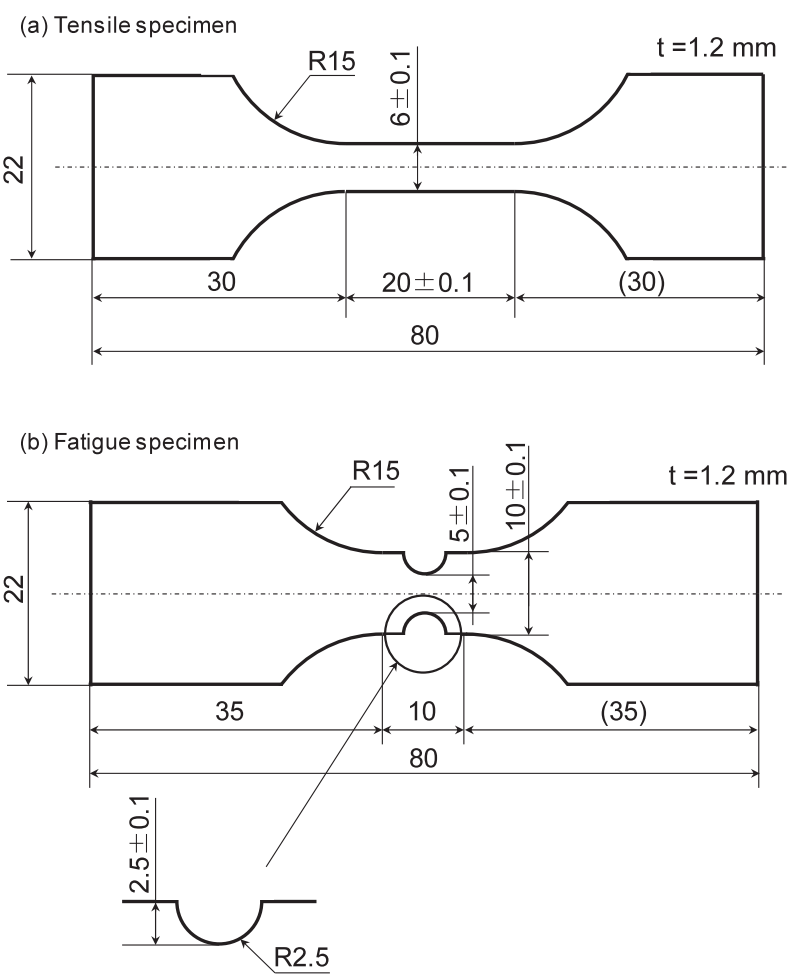

Fig. 2. Dimensions of (a) tensile and (b) fatigue specimens. The unit in these samples are in $\mathrm{mm}$.

operated at an acceleration voltage of $15 \mathrm{kV}$.

The volume fraction of the retained austenite $\left(f_{\gamma}\right)$ was obtained by the integrated intensities of diffraction peaks of $(200)_{\alpha},(211)_{\alpha},(200)_{\gamma},(220)_{\gamma}$, and $(311)_{\gamma}$ measured by $\mathrm{Cu}-\mathrm{K} \alpha$ radiation. ${ }^{19)}$ The carbon concentration in the retained austenite $\left(C_{\gamma}\right)$ was estimated by Eq. $(2)^{20)}$ using a lattice parameter $\left(a_{\gamma}\left(\times 10^{-10} \mathrm{~m}\right)\right)$ measured from the $(200)_{\gamma},(220)_{\gamma}$, and $(311)_{\gamma}$ diffraction peaks of $\mathrm{Cu}-\mathrm{K} \alpha$ radiation.

$$
\begin{aligned}
a_{\gamma}= & 3.5780+0.0330 \mathrm{C}_{\gamma}+0.00095 \mathrm{Mn}_{\gamma}+0.0056 \mathrm{Al}_{\gamma} \\
& +0.0220 \mathrm{~N}_{\gamma}+0.0051 \mathrm{Nb}_{\gamma}+0.0031 \mathrm{Mo}_{\gamma}
\end{aligned}
$$

where $\mathrm{Mn}_{\gamma}, \mathrm{Al}_{\gamma}, \mathrm{N}_{\gamma}, \mathrm{Nb}_{\gamma}$, and $\mathrm{Mo}_{\gamma}$ represent the chemical concentrations $(\operatorname{mass} \%)$ in the retained austenite, respectively. In this study, the chemical composition of the steel sheet was conveniently used.

Tensile tests were carried out on a servohydraulic testing system (8 872, Instron Corporation, High Wycombe, UK) at a crosshead speed of $1 \mathrm{~mm} / \mathrm{min}$ (i.e., strain rate of $8.33 \times$ $10^{-4} \mathrm{~s}^{-1}$ ) at $25^{\circ} \mathrm{C}$ using a tensile specimen with the gauge length of $15 \mathrm{~mm}$, width of $6 \mathrm{~mm}$, and thickness of $1.2 \mathrm{~mm}$, as shown in Fig. 2(a).

Load-controlled fatigue tests were conducted on a servohydraulic testing system (8872, Instron Corporation, High Wycombe, UK) with a sinusoidal waveform of 10 $\mathrm{Hz}$ at a stress ratio of 0.1 at $25^{\circ} \mathrm{C}$ using a fatigue specimen of $5 \mathrm{~mm}$ in width at notch root, $2.5 \mathrm{~mm}$ in radius of notch root, and $1.2 \mathrm{~mm}$ in thickness (Fig. 2(b)). The stress concentration factor at the notch tip was 1.6. The fatigue specimens were polished with waterproof papers \#320 and \#600 before the fatigue tests. The fatigue limit in this study was defined as the stress amplitude $\left(\Delta \sigma=\left(\sigma_{\max }-\sigma_{\min }\right) / 2\right)$ at which no failure occurred until $1 \times 10^{7}$ cycles. The net 
stress was adopted to evaluate the fatigue properties in this study.

\section{Results}

\subsection{Microstructure and Tensile Properties}

Figure 3 shows band contrast maps of the TRIP-aided steels analyzed by EBSD. The TM, TBM, and TBF steels exhibited a uniform and fine lath martensite matrix, bainitic ferrite-martensite matrices, and a uniform bainitic ferrite matrix, respectively. The retained austenite, of filmy type, was located at the lath boundaries in the TM and TBM steels. In addition, the martensite-austenite (MA) constituent, which consists of hard and fine martensite and fine retained austenite, existed at the prior austenite, packet, and block boundaries in the TM steels. The addition of nitrogen refined the structure of the lath matrices in all the TRIP- aided steels, and the retained austenite was changed from a filmy to blocky type.

Figure 4 shows the weight fraction of $\mathrm{NbC}$ and $\mathrm{AlN}$ at equilibrium in the chemical component systems of steels A $(\mathrm{N}=0 \mathrm{ppm}), \mathrm{B}(100 \mathrm{ppm})$, and $\mathrm{C}$ (200 ppm) calculated by Thermo Calc. $\mathrm{NbC}$ of $0.06 \mathrm{wt} \%$ was exhibited at a temperature between 200 and $900^{\circ} \mathrm{C}$ in all steels. Moreover, $0.03 \mathrm{wt} \%$ and $0.06 \mathrm{wt} \%$ of AlN was precipitated in steel B, with $100 \mathrm{ppm}$ of nitrogen, and steel C, with $200 \mathrm{ppm}$ of nitrogen, respectively. The inverse pole figures and phase maps of the AlN precipitated in the TM steels are shown in Fig. 5. The precipitation of AlN was not confirmed in steel A, whereas AlN with an approximate size of $10 \mu \mathrm{m}$ was observed in steel $\mathrm{B}$. In steel $\mathrm{C}$, coarse $\mathrm{AlN}$, with a size of approximately $25 \mu \mathrm{m}$ in the rolling direction, was observed.

Table 2 lists the tensile properties and retained austenite
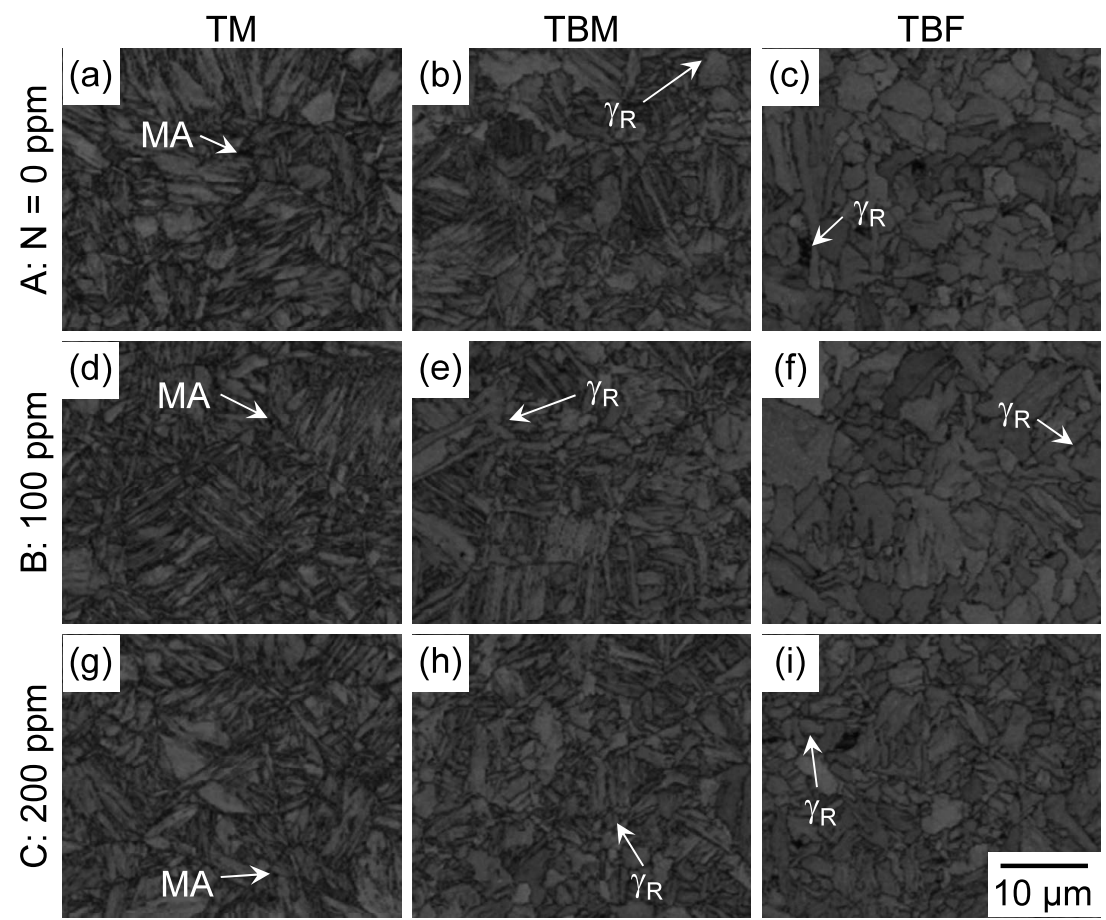

Fig. 3. Microstructures of ( $(a, d, g)$ TM, (b, e, h) TBM and (c, f, i) TBF steels added nitrogen of (a, b, c) 0 ppm, (d, e, f) $100 \mathrm{ppm}$ and $(\mathrm{g}, \mathrm{h}, \mathrm{i}) 200 \mathrm{ppm} . \gamma_{R}$ and MA represent retained austenite and martensite-austenite constituent, respectively.
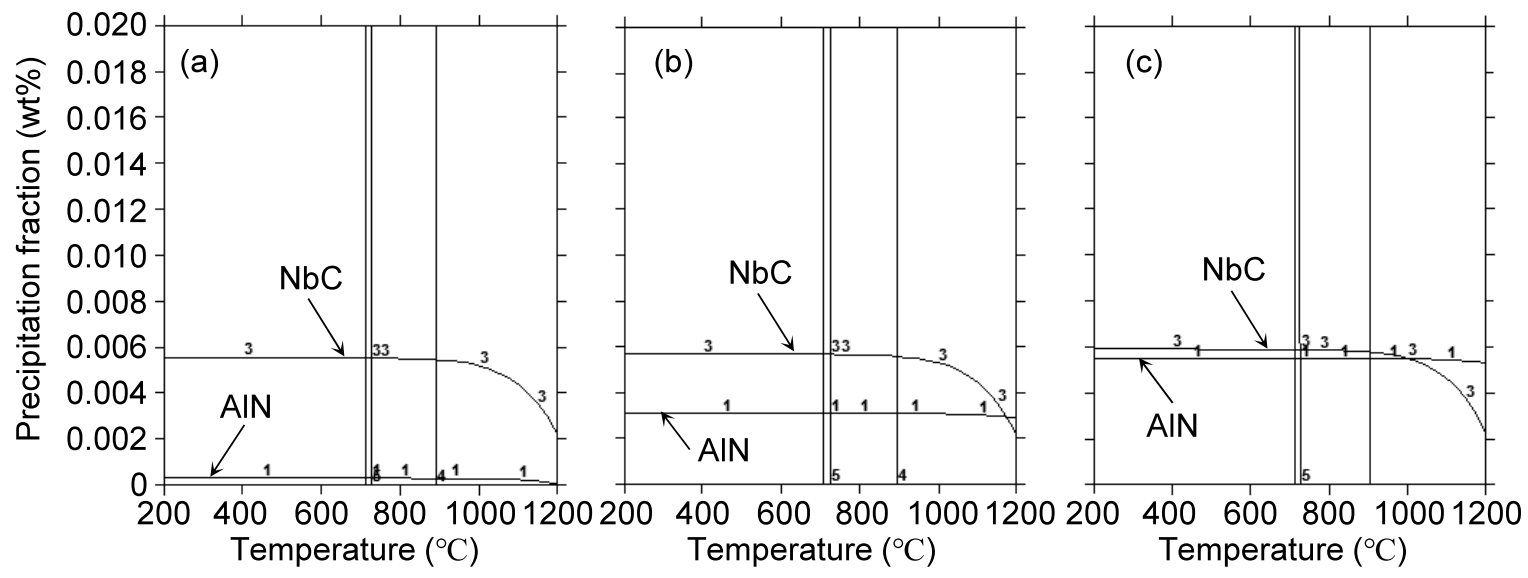

Fig. 4. Variations in weight fraction of $\mathrm{NbC}$ and $\mathrm{AlN}$ at equilibrium in chemical component systems as a function of temperature calculated by Thermo Calc in steels (a) A, (b) B and (c) C. 
characteristics of the TRIP-aided steels. The TM steels exhibited a tensile strength (TS) of $1370 \mathrm{MPa}$ grade and total elongation (TEl) of $13.8 \%-15.1 \%$. In TBM steels, TS of $1180 \mathrm{MPa}$ grade and TEl of $11.7 \%-16.1 \%$ were obtained. Moreover, the TS and TEl of the TBF steels were $980 \mathrm{MPa}$ grade and $23.5 \%-25.1 \%$, respectively. The addition of nitrogen slightly increased the $T S$, whereas $T E l$ was hardly altered. The volume fraction of the retained austenite $\left(f_{20}\right)$ and the carbon concentration $\left(C_{\gamma 0}\right)$ of the TM steels were $3.0-3.2 \mathrm{vol} \%$ and $0.62-0.85$ mass $\%$, respectively. In the TBM steels, $f_{\gamma 0}$ of $3.8-4.7$ vol $\%$ and $C_{\gamma 0}$ of $1.18-1.41$ mass $\%$ were obtained. The TBF steels exhibited $f_{\gamma 0}$ of $2.7-4.2 \mathrm{vol} \%$ and $C_{\gamma 0}$ of $0.74-0.93$ mass $\%$. The $f_{\gamma 0}$ and the $C_{20}$ increased due to the nitrogen addition of $100 \mathrm{ppm}$ in the three types of the ultrahigh-strength TRIP-aided steels, whereas the $C_{\gamma 0}$ of the TBM and TBF steels decreased with the addition of $200 \mathrm{ppm}$ of nitrogen.

\subsection{Fatigue Properties}

Figure 6 shows the relationship between stress amplitude
Table 2. Retained austenite characteristics, tensile properties and fatigue property of TRIP-aided steels with different matrix structure.

\begin{tabular}{|c|c|c|c|c|c|c|c|c|}
\hline & Steel & $f_{\gamma 0}$ & $C_{\gamma 0}$ & $Y S$ & $T S$ & $U E l$ & $T E l$ & $\sigma_{\mathrm{W}}$ \\
\hline \multirow{3}{*}{ A } & TM & 3.0 & 0.62 & 1048 & 1390 & 5.4 & 14.2 & 270 \\
\hline & TBM & 3.8 & 1.37 & 1031 & 1140 & 4.0 & 11.7 & 261 \\
\hline & TBF & 3.3 & 0.82 & 677 & 849 & 13.2 & 25.0 & 252 \\
\hline \multirow{3}{*}{ B } & TM & 3.0 & 0.63 & 994 & 1395 & 6.2 & 13.8 & 243 \\
\hline & TBM & 3.9 & 1.41 & 860 & 1181 & 5.5 & 16.1 & 270 \\
\hline & TBF & 2.7 & 0.93 & 692 & 849 & 12.0 & 25.1 & 252 \\
\hline \multirow{3}{*}{$\mathrm{C}$} & $\mathrm{TM}$ & 3.2 & 0.85 & 1101 & 1401 & 6.3 & 15.1 & 234 \\
\hline & TBM & 4.7 & 1.18 & 930 & 1103 & 4.6 & 12.3 & 243 \\
\hline & $\mathrm{TBF}$ & 4.2 & 0.74 & 663 & 855 & 13.4 & 23.5 & 234 \\
\hline
\end{tabular}

$f_{\gamma 0}($ vol $\%)$ : initial volume fraction of retained austenite, $C_{\gamma 0}(\mathrm{mass} \%)$ : initial carbon concentration in retained austenite. $T S(\mathrm{MPa})$ : tensile strength, YS (MPa): yield strength, $T E l(\%)$ : total elongation, $U E l(\%)$ : uniform elongation $\sigma_{\mathrm{W}}(\mathrm{MPa})$ : fatigue limit
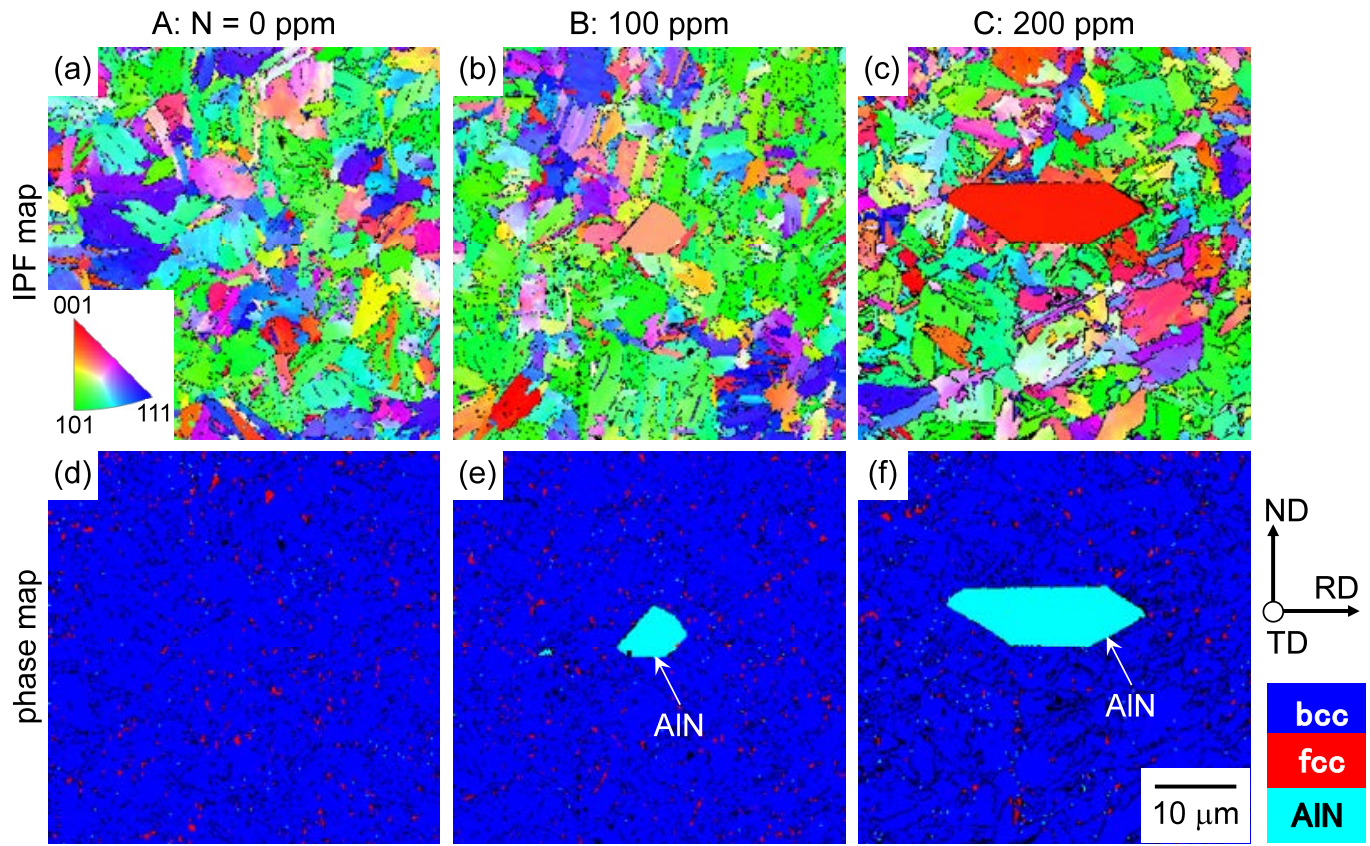

Fig. 5. (a, b, c) Inverse pole (IPF) figure and (d, e, f) phase maps of steels (a, d) A, (b, e) B and (c, f) C. ND, RD and TD represent normal direction, rolling direction and transverse direction, respectively. (Online version in color.)
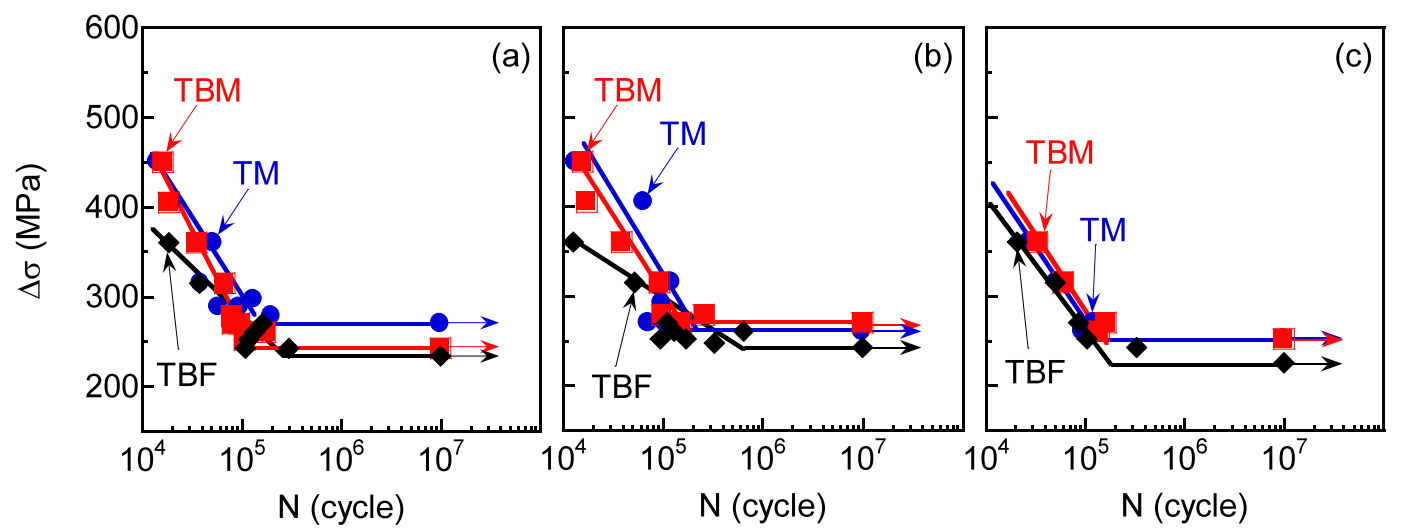

Fig. 6. $S-N$ curves of TM, TBM and TBF steels of steels (a) A, (b) B and (c) C. (Online version in color.) 
$\left(\Delta \sigma=\left(\sigma_{\max }-\sigma_{\min }\right) / 2\right)$ and number of cycles to failure $(N)$ in the ultrahigh-strength TRIP-aided steels. The variation in fatigue limit as a function of tensile strength (TS) in the ultrahigh-strength TRIP-aided steels is shown in Fig. 7 and Table 2. The fatigue limits of the TM and the TBM steels were higher than that of the TBF steels regardless of the nitrogen contents (Figs. 6, 7). The addition of $100 \mathrm{ppm}$ nitrogen increased the fatigue limit, whereas the fatigue limit was decreased by the addition of 200 ppm nitrogen in all the types of TRIP-aided steels (Fig. 7). Figure 8 shows fracture surfaces at the crack initiation regions, which correspond to the notch root in the TRIP-aided steels. The fracture surfaces revealed that the fatigue crack initiated at the inclusion located near the notch root. Particularly, steels B with 100 ppm nitrogen and C with 200 ppm nitrogen exhibited a large size inclusion at the notch root in com-

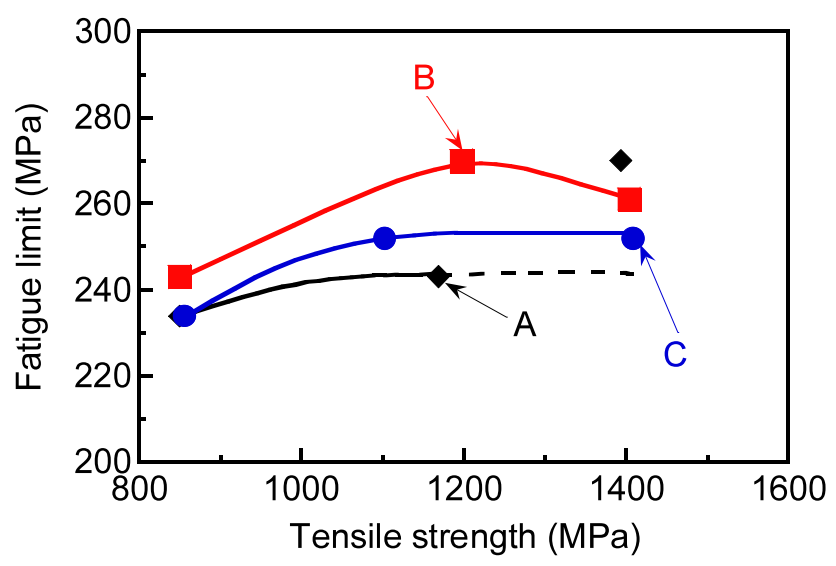

Fig. 7. Variations in fatigue limit as a function of tensile strength in ultrahigh-strength low alloy TRIP-aided steels. (Online version in color.) parison with steel A, which was the base steel. It is noted that the fracture surfaces at the fatigue crack propagation region exhibited the typical fatigue fracture morphology in the TRIP-aided steels.

Figure 9 shows SEM images of the fatigue surface cracks in steel A. To observe the main fatigue surface cracks, the fatigue tests were stopped at $N=33897$ cycles for the TM steel, $N=26213$ cycles for the TBM steel and $N=16416$ cycles for the TBF steel. Regardless of the matrix types of the TRIP-aided steels, the crack propagated at the lath, block, and packet boundaries. In the TM steel, the crack propagated accompanied by a small amount of slip band at the vicinity of the crack tip. In the TBM steel, the propagation of the crack was accompanied by the formation of a slip band at the bainitic ferrite matrix. On the other hand, the slip band around the crack tip in the TBF steel was small compared with that in the TM and TBM steels. It is noted that the crack propagation behavior of steels $B$ and $C$ had a tendency similar to that of steel $\mathrm{A}$, even though nitrogen was added to steels B and C.

Figure 10 shows IPF and phase maps analyzed by EBSD of branched crack tip of fatigue-fractured TM, TBM and TBF steels of the steel A. The EBSD analyses were conducted in an area of $15 \mu \mathrm{m} \times 15 \mu \mathrm{m}$ with a beam step size of $0.05 \mu \mathrm{m}$ operated at an acceleration voltage of $15 \mathrm{kV}$. The crack propagated along the block, packet and prior grain boundaries in the TRIP-aided steels as explained in Fig. 10. It is noted that the retained austenite at the vicinity of crack disappeared. This fact implies that the retained austenite around the crack transformed to martensite due to the crack propagation during fatigue tests.
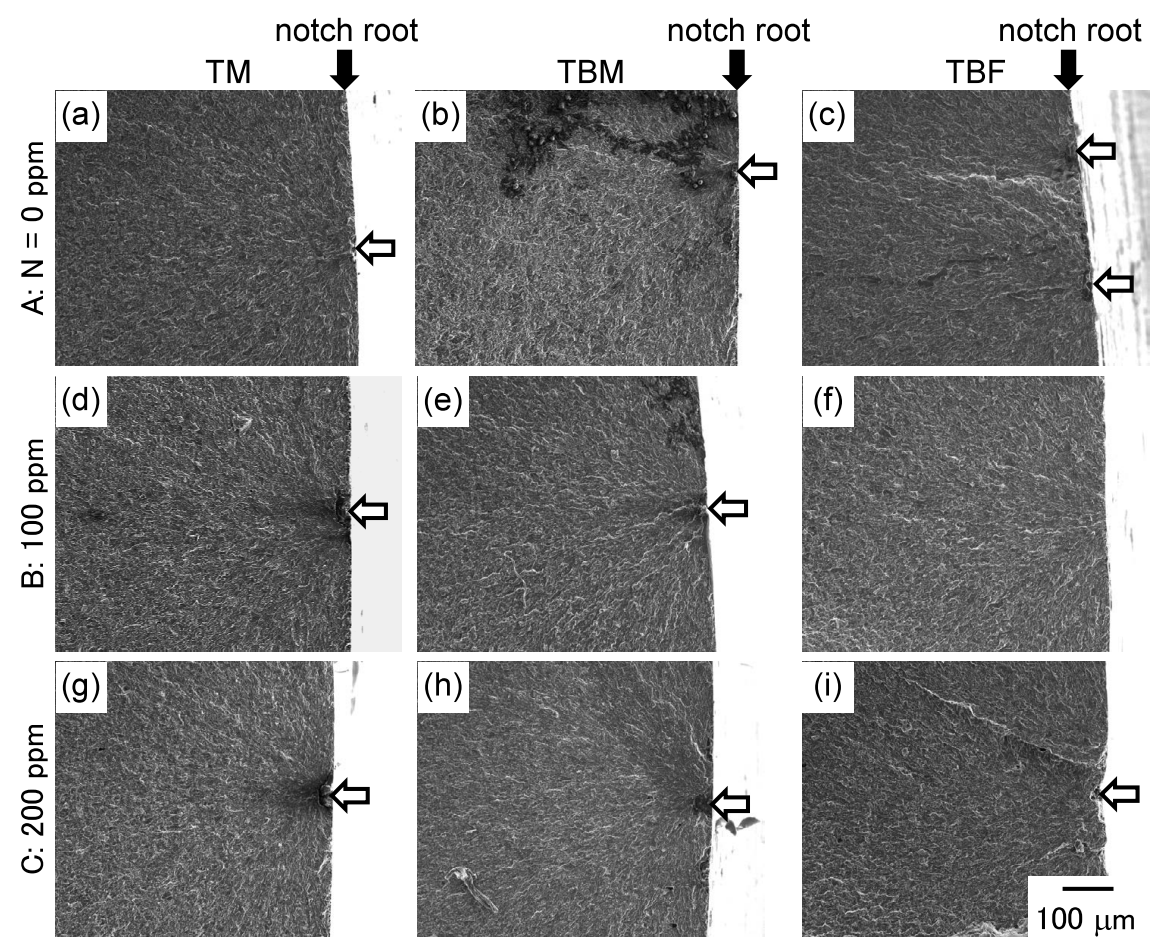

Fig. 8. Fracture surfaces of ( $(a, d, g) T M,(b, e, h) T B M$ and (c, f, i) TBF steels of steels (a, b, c) A, (d, e, f) B and (g, h, i) C. The white arrows represent inclusions. 

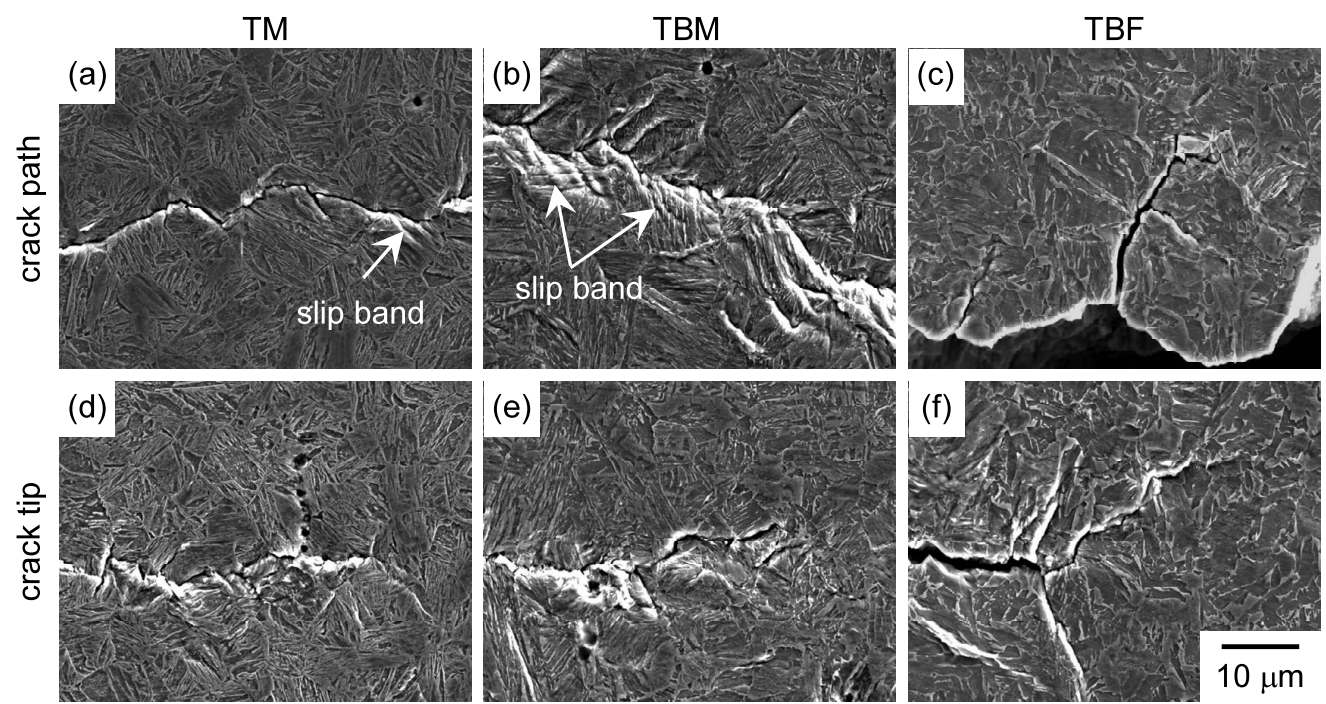

Fig. 9. Scanning electron micrographs of (a, b, c) crack path and (d, e, f) crack tip of (a, d) TM $(\Delta \sigma=400 \mathrm{MPa}, \mathrm{N}=$ 33897 cycles), (b, e) TBM ( $\Delta \sigma=400 \mathrm{MPa}, \mathrm{N}=26213$ cycles) and (c, f) TBF steels $(\Delta \sigma=400 \mathrm{MPa}, \mathrm{N}=16416$ cycles) of steel A.
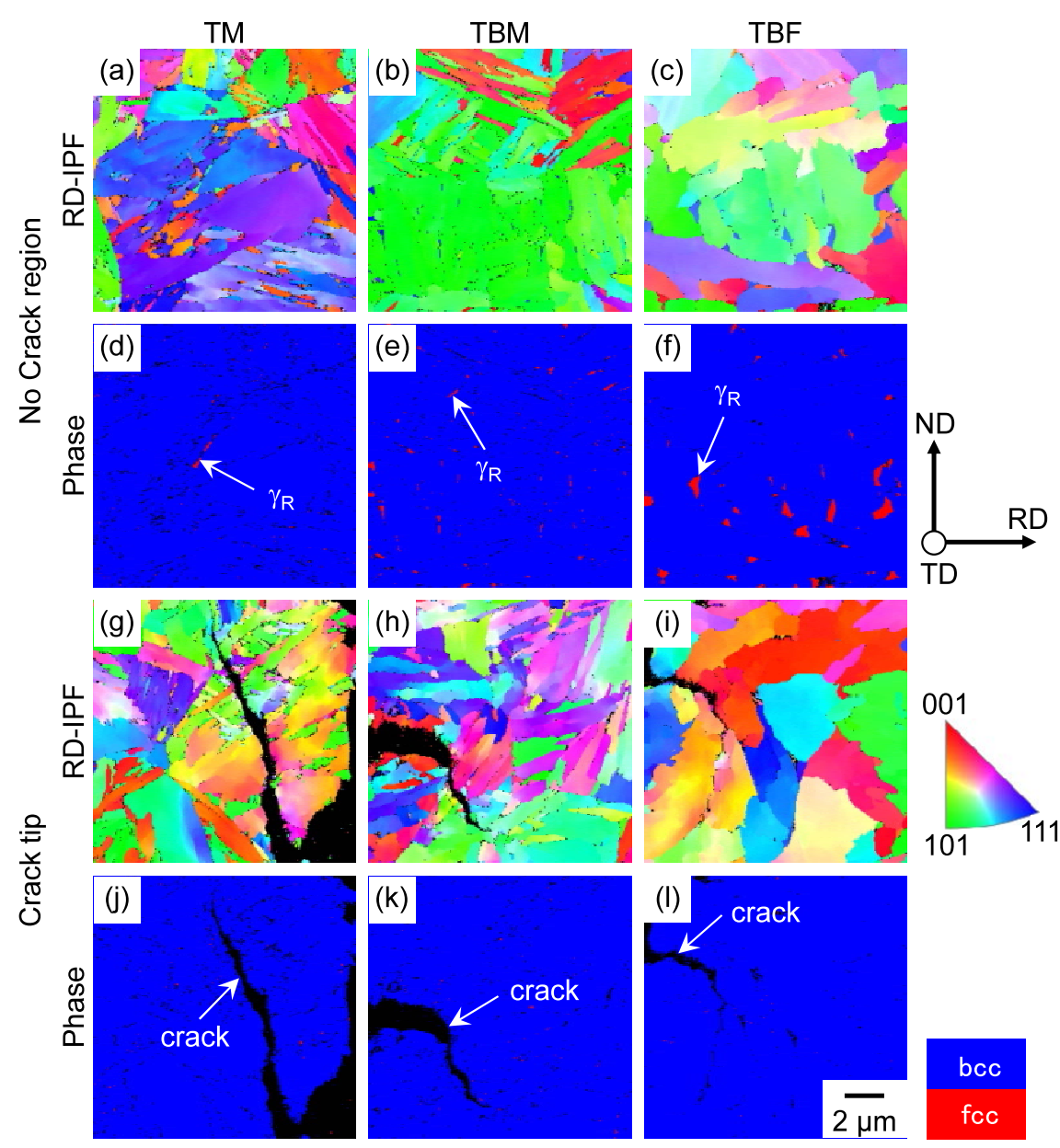

Fig. 10. (a-c, g-i) RD-Inverse pole figure (RD-IPF) and (d-f, $j-1)$ phase maps of the regions (a-f) without and (g-l) with branched cracks of the fatigue-fractured (a, d, g, j) TM $(\Delta \sigma=297 \mathrm{MP}),(\mathrm{b}, \mathrm{e}, \mathrm{h}, \mathrm{k}) \mathrm{TBM}(\Delta \sigma=270 \mathrm{MP})$ and (c, f, $\mathrm{i}, 1) \mathrm{TBF}(\Delta \sigma=261 \mathrm{MP})$ steels of steel A. ND, RD and TD represent normal direction, rolling direction and transverse direction, respectively. (Online version in color.)

\section{Discussion}

\subsection{Effect of Matrix Morphology}

It has been reported that the behavior of fatigue crack propagation in TRIP-aided steels depends on (i) the plastic deformation resistance of the matrix and transformed martensite and (ii) the relaxation of stress concentration due to the strain-induced transformation of the retained austen- 
ite. $^{21-23)}$ Regarding (i) the plastic deformation resistance of the matrix, a high crack propagation resistance might be obtained in the TM and the TBM steels. This occurs because the TM steels with martensite matrix and the TBM steels with martensite-bainitic ferrite matrices exhibited higher TS than the TBF steels with bainitic ferrite matrix. In addition, the strain-induced martensite improved the work hardening rate, which is due to the existence of transformed martensite containing high carbon concentration. Thus, the straininduced transformation of the retained austenite might also affect the plastic deformation resistance and improve the crack propagation resistance of the TRIP-aided steels. With respect to (ii) the relaxation of stress concentration due to the strain-induced transformation of the retained austenite, Sugimoto et al. $^{23)}$ investigated the fatigue properties of the low alloy TRIP-aided steels at a fatigue testing temperature ranging between 20 and $200^{\circ} \mathrm{C}$ to clarify the role of strain-induced transformation of the retained austenite against the fatigue properties. They reported that the propagation of cracks was suppressed by the plastic relaxation of local stress concentrations due to the transformation of the retained austenite around the slip band and, as a result, the stability of the retained austenite affected the fatigue strength. In the present study, the retained austenite around the crack transformed to martensite as shown in Fig. 10. In addition, transformation-induced crack closure ${ }^{24,25)}$ may be obtained because volume expansion accompanying the martensitic transformation occurs in the ultrahigh-strength TRIP-aided steels that exhibit a uniform distribution of fine retained austenite. Particularly, TBM steels tend to exhibit a high volume fraction and high carbon concentration in retained austenite in comparison with other TRIP-aided steels, as shown in Fig. 11. Thus, it was suggested that the TBM steels effectively suppressed the fatigue crack propagation because of the relaxation of stress concentration at the fatigue crack tip and the transformation-induced crack closure due to the strain-induced transformation of the retained austenite. Moreover, it is known that the stability of the retained austenite was affected by not only its carbon concentration but also its morphology ${ }^{26-28)}$ and surrounded matrix. $^{26-28)}$ In the TM and the TBM steels, the retained austenite films were located at the martensite and bainitic ferrite lath, block, and packet boundaries, and the fine retained austenite existed as MA constituent surrounded by hard martensite at the triple junctions of the prior austenite grain boundaries. The filmy and fine retained austenite was considered to have high stability against the strain-induced martensitic transformation. Thus, austenite can remain until the crack tip reaches it, and the relaxation of stress concentration due to the strain-induced transformation of the retained austenite at the crack tip suppressed the propagation of fatigue cracks. Therefore, it was considered that the TM and the TBM steels exhibited a higher fatigue strength than that of the TBF steels. In particular, the TBM steels exhibited a level of fatigue strength similar to that of the TM steels, although the TS of the TBM steels was lower than that of the TM steels.

\subsection{Effect of Nitrogen Addition}

The mechanical properties of the low alloy TRIP-aided steels with a chemical composition of $0.2 \mathrm{C}-1.5 \mathrm{Si}-1.5 \mathrm{Mn}-$ 0.04Al (mass\%) have been investigated by Baik et al., ${ }^{29)}$ and they have reported that the TS and ductility of the TRIPaided steels were improved by the addition of $100 \mathrm{ppm}$ of nitrogen. It was concluded that the improvements in both $T S$ and ductility might be caused by the increase in the volume fraction of retained austenite. The reason is the delay in the ferrite and/or bainite transformations during cooling from the intercritical annealing and austempering treatment due to the AIN precipitated in the matrix, the refinement of the microstructure due to the pinning effect of AlN precipitation at the grain boundaries, and the strengthening of the matrix microstructure due to the solid solution hardening. In this study, similar effects were expected to be obtained because approximately $0.03 \mathrm{wt} \%$ and $0.06 \mathrm{wt} \%$ of $\mathrm{AlN}$ were precipitated in steels B and C, respectively (Fig. 4). In addition, carbon concentration to the retained austenite during isothermal treatment was expected to occur efficiently because TM, TBM, and TBF steels exhibited a fine retained austenite. According to the observed microstructure (Fig. 3 ) and the analysis of the characteristics of the retained austenite (Table 2), the refinement of the microstructure and the increase in carbon concentration in the retained austenite were achieved by the addition of nitrogen, and those factors increased the fatigue strength of steel B, with 100 ppm of nitrogen. However, a large amount of coarse AIN was precipitated in the nitrogen-added TRIP-aided steels (Figs. 4, 5) because 0.5 mass $\%$ of aluminum was also added to the TRIP-aided steels. Thus, it was considered that the refinement of the microstructure due to the pinning

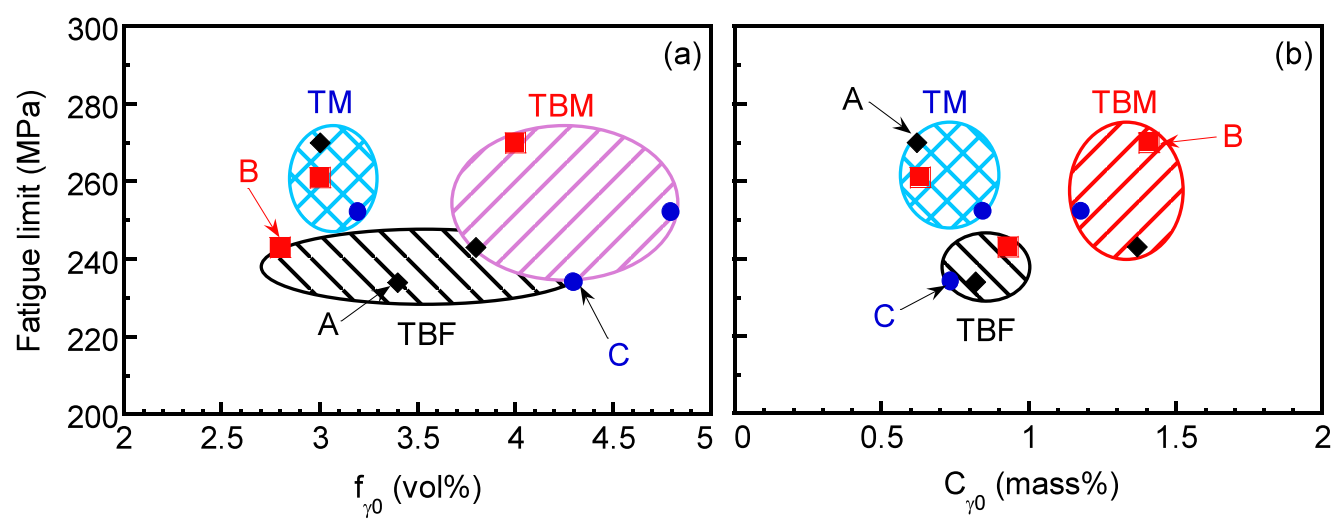

Fig. 11. Variations in fatigue limit as functions of (a) initial volume fraction of retained austenite $\left(f_{\gamma 0}\right)$ and (b) initial carbon concentration in retained austenite $\left(C_{\gamma 0}\right)$ in ultrahigh-strength TRIP-aided steels. (Online version in color.) 


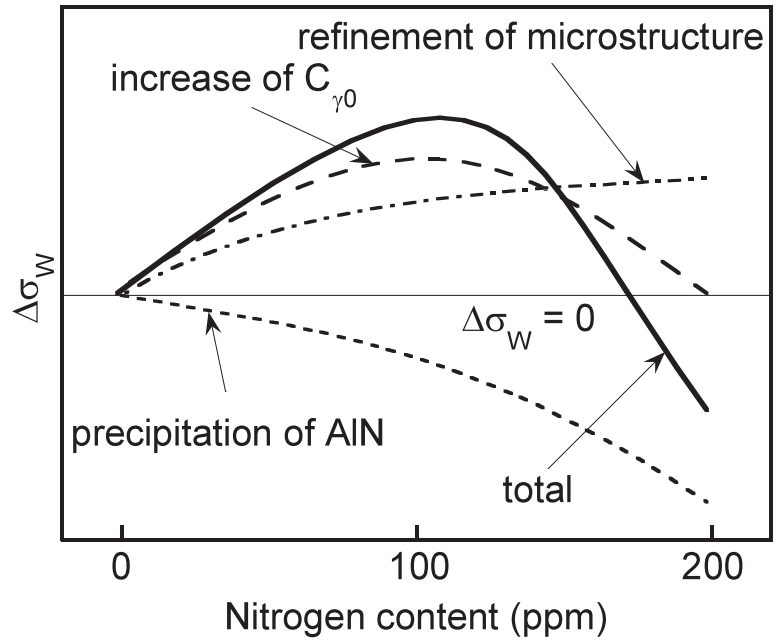

Fig. 12. Illustration of effects of refinement of microstructure, increase of initial carbon concentration in retained austenite $\left(C_{\gamma}\right)$ and precipitation of AlN on change in the fatigue limit $\left(\Delta \sigma_{\mathrm{W}}\right)$ in TRIP-aided steels.

effects of the AIN precipitation and the strengthening of the matrix because of the solid solution strengthening were not sufficiently obtained. In steel C, with 200 ppm of nitrogen, the large size of AlN might act as a stress concentration site, accelerating the fatigue crack initiation. In addition, the fatigue crack propagation was also accelerated due to the coalescence of cracks initiated at the coarse AlN or AIN/ matrix interfaces. The effects of nitrogen addition on the fatigue properties of the TRIP-aided steels are summarized in Fig. 12. It was concluded that the addition of $100 \mathrm{ppm}$ of nitrogen improved the fatigue strength due to the improvement in carbon concentration and the refinement of the microstructure, whereas the addition of $200 \mathrm{ppm}$ of nitrogen deteriorated the fatigue strength due to the precipitation of a large amount of coarse AlN.

\section{Conclusions}

The effects of the microstructure and nitrogen addition on the fatigue properties of the ultrahigh-strength TRIP-aided steels were investigated to improve their mechanical performance regarding their application to automotive structural parts. The results are summarized as follows.

(1) TM and TBM steels exhibited high fatigue strength in comparison with TBF steels. This may have been caused by three factors: (i) the fine and uniform martensite and/or bainitic ferrite matrices, (ii) the existence of stable retained austenite along the lath, block, and packet boundaries and MA constituent, and (iii) the increase in tensile and yield strengths due to the low temperature of the isothermal transformation treatment.

(2) The fatigue strength of ultrahigh-strength low alloy TRIP-aided steels was improved by the addition of $100 \mathrm{ppm}$ of nitrogen. The suppression of the crack propagation could be achieved by the refinement of the martensite and bainitic ferrite matrices due to the precipitation of AlN and by the effective relaxation of stress concentration at the crack tip because of the volume expansion associated with straininduced transformation of the retained austenite.

(3) The increase in nitrogen content from $100 \mathrm{ppm}$ to $200 \mathrm{ppm}$ deteriorated the fatigue properties of the TRIPaided steels. This may have been caused by the promotion of crack initiation and propagation due to the coarse AlN, which acts as a stress concentration site, even though the TRIP-aided steels with 200 ppm of nitrogen achieved a refined microstructure.

\section{Acknowledgment}

The authors gratefully acknowledge the financial support obtained through grants from The Iron and Steel Institute of Japan (2012).

\section{REFERENCES}

1) V. F. Zackay, E. R. Parker, D. Fahr and R. Bush: Trans. Am. Soc. Met., 60 (1967), 252.

2) K. Sugimoto, T. Iida, J. Sakaguchi and T. Kashima: ISIJ Int., 40 (2000), 902.

3) S. Song, K. Sugimoto, M. Kobayashi, H. Matsubara and T. Kashima: Tetsu-to-Hagané, 86 (2000), 563 (in Japanese).

4) T. Hojo, K. Sugimoto, Y. Mukai and S. Ikeda: ISIJ Int., 48 (2008), 824.

5) A. Nagasaka, Y. Kubota, K. Sugimoto, A. Mio, T. Hojo, K. Makii, M. Kawajiri and M. Kitayama: ISIJ Int., 50 (2010), 1441.

6) J. Kobayashi, S. Song and K. Sugimoto: ISIJ Int., 52 (2012), 1124.

7) S. Xia, F. Zhang and Z. Yang: Mater. Sci. Eng. A, 724 (2018), 103.

8) J. Kobayashi, D. Ina, Y. Nakajima and K. Sugimoto: Metall. Mater. Trans. A, 44 (2013), 5006.

9) J. Kobayashi, N. Yoshikawa and K. Sugimoto: ISIJ Int., 53 (2013), 1479.

10) K. Sugimoto, M. Murata and S. Song: ISIJ Int., 50 (2010), 162.

11) K. Sugimoto, M. Tsunezawa, T. Hojo and S. Ikeda: ISIJ Int., 44 (2004), 1608.

12) F. Bahrami and A. Hendry: Mater. Sci. Technol., 11 (1995), 488

13) A. A. Ono, N. Alonso and A. P. Tschiptschin: ISIJ Int., 36 (1996), 813.

14) T. Shimizu, T. Koga and T. Noda: Denki Seiko, 73 (2002), 87 (in Japanese).

15) H. J. Grabke: ISIJ Int., 36 (1996), 777

16) Y. Murakami and M. Endo: Int. J. Fatigue, 16 (1994), 163.

17) K. Sugimoto, T. Hojo and A. K. Srivastava: Metals, 8 (2018), No. 5, 355.

18) I. Tamura: Strength of Steels, Nikkan Kogyo Shimbun, Tokyo, (1970), 40 (in Japanese).

19) H. Maruyama: J. Jpn. Soc. Heat Treat., 17 (1977), 198 (in Japanese).

20) D. J. Dyson and B. Holmes: J. Iron Steel Inst., 208 (1970), 469.

21) K. Sugimoto, S. Song, K. Inoue, M. Kobayashi and S. Masuda: J. Soc. Mater. Sci., Jpn., 50 (2001), 657 (in Japanese).

22) S. Song, K. Sugimoto, S. Kandaka, A. Futamura, M. Kobayashi and S. Masuda: J. Soc. Mater. Sci., Jpn., 50 (2001), 1091 (in Japanese).

23) K. Sugimoto, X. Sun, M. Kobayashi, T. Haga and H. Shirasawa: Trans. Jpn. Soc. Mech. Eng. A, 63 (1997), 717 (in Japanese).

24) Z. Mei and J. W. Morris, Jr.: Eng. Fract. Mech., 39 (1991), 569.

25) Y. Nishikura, M. Koyama, Y. Yamamura, T. Ogawa, K. Tsuzaki and H. Noguchi: Int. J. Fatigue, 113 (2018), 359.

26) I. B. Timokhina, P. D. Hodgson and E. V. Pereloma: Metall. Mater. Trans. A, 35 (2004), 2331.

27) X. C. Xiong, B. Chen, M. X. Huang, J. F. Wang and L. Wang: Scr. Mater., 68 (2013), 321.

28) F. G. Caballero, C. Garcia-Mateo, J. Chao, M. J. Santofimia, C. Capdevila and C. G. Andes: ISIJ Int., 48 (2008), 1256.

29) S. C. Baik, S. Park, O. Kwon, D. Kim and K. Oh: ISIJ Int., 46 (2006), 599. 